\title{
Teaching Reforms Based on College-Enterprise Cooperation
}

\author{
Xucheng Liü, Wang Hongtao*, Huang Hui, He Yuebang, He Yihong \\ School of Information Engineering \\ Wuyi University \\ Jiangmen, China \\ alxchk@outlook.com,*nushongtaowang@qq.com, \\ Yang Dongyu, Jia Shizhun, Xie Langxiong \\ The fifth Research Institute of The Ministry of Industry and Information Technology of China \\ Guangzhou, China
}

\begin{abstract}
The college-enterprise cooperation is an effective method to cultivate innovative and applied talents facing enterprises, achieving the transformation of student status to staff. In this model, the resources of college and enterprises could be exchanged more efficiently to maximize the mutual benefits, with meeting the demands of both, relying on the support of college and enterprises to explore the best approaches for teaching reform. As an application of this method, the practice of Wuyi University and the Fifth Research Institute of the Ministry of Industry and Information Technology of China have employed some new approaches: compensation of course cre dit and interest matching (software design or hardware design), and after a three-years' study, students will train in the enterprise at last year.
\end{abstract}

Keywords-The College-Enterprise Cooperation; Teaching Reform; Compensation of Course Credit; Interest Matching

\section{INTRODUCTION}

Since the 21 century, with the rapid improvement of economic and industrialization stage, China has become an industrial power, which is the most important industrial area of the world. Before celebrating the achievement of the effort of our country, even if colleges and enterprises are becoming more and more closely related, the employment problem of graduates from college has attracted great attention from society and government. At present, we can't handle the relation between study in the college and practice in the enterprises, resulting in graduates from college can understand specialty theory. However, the enterprises do not think highly of that. Comparing with theory, they prefer the students with more practical abilities, ensuring they can create value for enterprises in a short time. The transform is difficult for graduates from students to qualified staff. Moreover, we have to realize that there are many workers in China, but less qualified engineers. The engineering education of China has many problems [1]:

This study was supported by Education Reform Project of Wuyi University No. 30727019 and No. JX201714, Undergraduate Teaching Quality and Teaching Reform Project in Wuyi University (JX2017001), Guangdong Undergraduate Teaching Quality and Teaching Reform Project (GDJX2017002).
1) Talents training model lacks diversity, hierarchy, and adaptability.

2) The problem of lacking engineering practice for graduates has not been solved for a long time.

3) Valuing the evaluation system and papers, but looking down on the design and lacking of practice.

4) Lacking of industry-college-government cooperation.

5) Enterprises do no put a high value on the process of cultivating talents.

The college education always stay away from enterprises, thus can't meet the demands of each other, leading to enterprises are hard to find qualified staff, but too many graduates bother they can't find a suitable occupation, these problems stimulate the employment competition, and increase the pressure on students' employment [2].

In the research of Mckinsey: by 2020, the technology enterprises lack more than 40 million technical talents, and, in China, we need more than 22 million technical talents [3]. Now, all colleges and universities value the cooperation with enterprises to cultivate the practical ability of students and the teaching reform.

\section{THE REQUIREMENTS OF BOTH COLLEGE AND ENTERPRISE}

With the development of high education reform and the rapid improvement of needs by society, making that colleges' objective must accord with the enterprise' needs [4], thus, the cooperation between colleges and enterprises is becoming more and more closely. No matter what kind of teaching mode is reflected, the talent cultivation of the college closely surrounds the needs of the enterprise and the market [5].

\section{A. Responsibilities and Needs of College}

For college, their responsibilities are guiding students and encouraging them to concentrate on more professional knowledge: on the one hand, to cultivate more students with good basic skills; on the other hand, to cultivate creative researchers. Not only that, but the students' humanistic quality 
and quality education can't be lacking, so that students can have a complete personality, and such education can be regarded as qualified education. At the time to improve the entire education quality, the college must improve the teachers' teaching quality by teaching reform, like building an excellent teaching quality evaluation system to keep the enthusiasm of teaching. Moreover, young teachers are the important component of a college education, and improving their ability is good for optimizing the age structure of teachers. They are the future of education area after all. Besides, setting up a specialty with a distinctive and advantageous position, it requires the college to follow the market discipline and meet their demands after equipping teachers with excellent quality [6]. Nevertheless, it has to cost a long time to ensure the education quality of college to cultivating innovatively and applied students.

\section{B. The Responsibilities and Needs of Enterprise}

Enterprises are very realistic that they want high-quality staff to earn profit. That requires enterprises to promote their popularity and build a characteristic culture to enhance their competitiveness. Enterprises should discover the significant impact of colleges in cultivating talents and have the vision with long-term and development, finding a common ground of benefits with colleges. Moreover, enterprises should bear social responsibility which includes not only to protect the environment and to support the local community, but also to encourage colleges to struggle to cultivate professional talents.

The relation between colleges and enterprises should be closely and harmonious. Because of the imperfect of the policy of government, both should deal with cooperation seriously, designing a suitable cooperation target and content, trying to coordinate with each other, making sure that both maximize the benefits of each other. It is an act of combining the innovation science and technology with economic development about colleges-enterprises cooperation. Specifically, it is reflected in the colleges subject system and enterprise occupation, cultivating the students' practice ability, using the knowledge from college to training, finally, applied to the daily production and management.

\section{THE TEACHING REFORM OF WUYI UNIVERSITY}

In recent decades, the manufacturing industry and artificial intelligence have been changed dramatically [7]. The object of this teaching reform is to build a college-enterprise cooperation modal. The proposed modal in the present work is shown in Fig.1.
Project Originates from the Needs of Enterprise

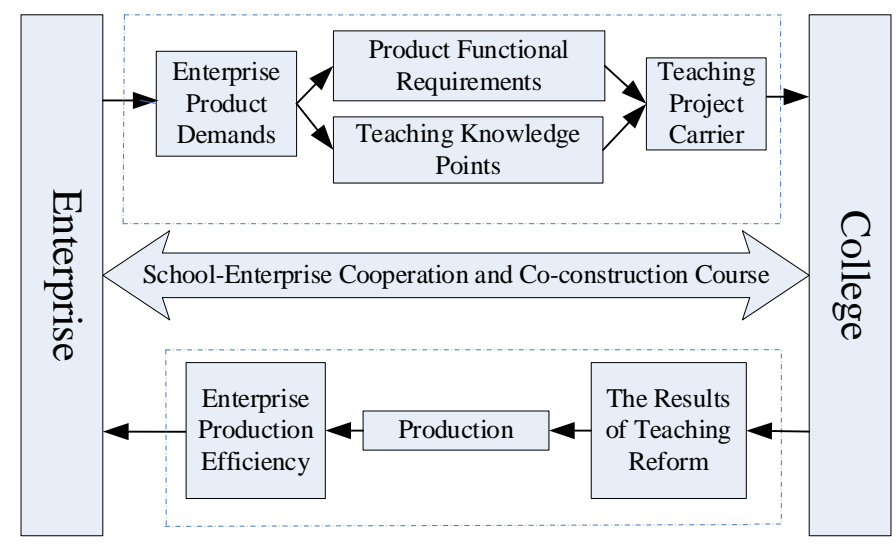

Improving the Efficiency of Enterprises by Teaching Achievement

Fig. 1. The proposed college-enterprise cooperation modal

To reduce the differences between the demands of enterprise and the college education, an education reform is required in Wuyi University's School of Information Engineering as follows:

\section{A. Holding Academic Lecture to Improve Teacher's Research Abilities}

The ability of teachers' research and teaching is one of the most important component of college education [8], thus inviting experts to held specific lecture is a regular activity, like artificial intelligence, machine vision, brain like calculation and signal processing. Also, the establishment of an incentive system can encourage teachers' interest in teaching or academic level, and they can update their knowledge structure by academic exchange. Moreover, many conferences held in other cities we organize teachers and students to attend with financial support.

\section{B. Introducing College-Enterprise Cooperation and Inviting Them to Train in the Enterprise}

The Fifth Electronic Institute, which is established in 1955, is the earliest authoritative institute working about reliability research. All the junior students interested in that are invited to participate in this lecture. This is an opportunity for students and enterprise, and at the scene students can submit their resume. After a simple interview, the representatives of enterprise decide whom are the suitable objects to train. Wuyi University provides many opportunities for students to practice in the enterprise, making students find an occupation with their interest, or chances to visit various enterprise. As shown in Fig.2, the training venue provided by the Fifth Electronic Institute of the Ministry of Industry and Information Technology, which includes hardware and software. The most important and meaningful thing is that these students can have the opportunity to be trained under the standard research and development process. 


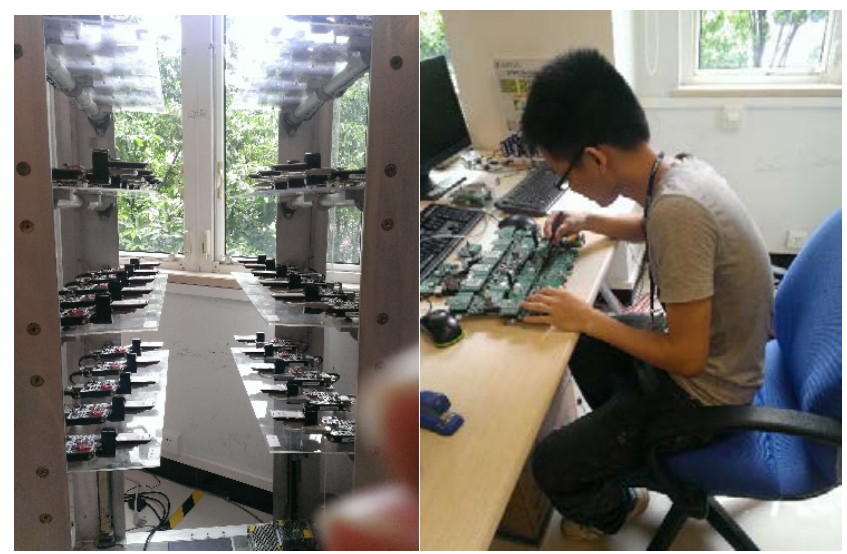

Fig. 2. The training venue provided by the Fifth Electronic Institute

\section{Participating Various Competition and Training Ability of Student}

We regularly organize many competitions every year, such as Holtek cup SCM application design contest, Freescale Cup national college students' intelligent car competition, national undergraduate electronics design contest and many competitions held by the college. Through these contests can build students' capacity about software or hardware design to meet the demands of enterprise or research work. No matter students want to work in an enterprise or study for a master's degree; these contests are the chance to prepare for future.

\section{THE COLLEGE-ENTERPRISE COOPERATION BETWEEN} WUYI UNIVERSITY AND THE FIFTH ELECTRONIC INSTITUTE

Government encourages college students when finishing knowledge study to train in the enterprises and society by using college-enterprise model. Not only the enterprise can recruit staff in college by a lower cost, saving time for cultivating practical talents, but also college can make sure most students will find a satisfied occupation or obtain perfect skills in work, which is the most important factor to find a good job with a satisfactory salary [9]. And government can solve the employment problem of students. This is win-win style cooperation between college and enterprise and government. Wuyi University cooperates with the Fifth electronic Institute to achieve the procedure from teaching in college to practicing in the enterprise for students to improve their competitive power.

\section{A. Optional Item for Students Based on Interest}

In consideration of students' specialty, we choose the students from the school of information engineering and the school of computer science. Two options can be chosen by students: software design and hardware design, which is the demands of most enterprise. About the software, the Fifth Electronic Institute will train the ability about design and maintain app of Android, IOS or Windows, and there are many groups they can join in, such as group of design Android or IOS mobile client, web application group and front-end development group. Students are required to cooperate with enterprise to complete the software part of project. On the other hand, the hardware design, as the project demands, requires students to design single chip microcomputer or circuit diagram, etc. In our previous study, we have applied CDIO concept in study theory, and practice students individual professional skills and interpersonal communication skills of professional courses [10]. Therefore, students not only learn knowledge form college, but also been trained the practical ability and the ability of applying theory to practice. In the present study, we chose sixteen students to participate in this college-enterprise cooperation program, the more details are summarized in table 1:

TABLE I. THE INFORMATION OF EMPLOYED ST UDENT S

\begin{tabular}{|c|c|c|c|}
\hline Specialty & Sex & Number & Desire \\
\hline \multirow{2}{*}{ Information Security } & Male & 5 & Software Design \\
\cline { 2 - 4 } & Female & 1 & Hardware Design \\
\hline \multirow{2}{*}{ Traffic Engineering } & Male & 4 & Software Design \\
\cline { 2 - 4 } & Female & 2 & Software Design \\
\hline \multirow{2}{*}{$\begin{array}{c}\text { Electrical Engineering } \\
\text { and Automation }\end{array}$} & Male & 2 & Hardware Design \\
\cline { 2 - 4 } & Female & 2 & Software Design \\
\hline
\end{tabular}

\section{B. Composition of Course Credit}

A significant reform of teaching and cooperation with enterprises is the policy of composition of course credit. There are many problems bothering students. One of the most significant problem is that they have not got enough credit to graduate. Thus students are hard deciding if they will participate in the college-enterprise cooperation program. Some students have the course causing that they do not have time to train in the enterprise what is a pity for them. Therefore, for the credit of elective course, college and enterprise decide students can get the credit from enterprise, but student must get the credit of required course in college. For example, they can't get the English course credit from an electronic enterprise to ensure the project is fair. This policy can save students' time from course to train in a realistic project, closely combining the education of college and the demands of enterprise to cultivate students' ability with purpose.

\section{THE SIGNIFICANCE AND FUTURE DEVELOPMENT TREND}

The most significant of school-enterprise cooperation is not only to take into account the integrity of college education and the specialty of technology, but also to consider the development needs of enterprises, to truly spare education resources and effectively improve employment rate of college students [11]. It is believed that this training will help to ensure the professionalism and effectiveness of college education. At the same time, it will strengthen students' professional ethics and cultivate a good corporate atmosphere.

In the future, the most harmonious college-enterprise cooperation envisaged should be the "integration of production, learning, research and application” model, in which colleges use their hardware facilities (classrooms, computers, 
multimedia facilities, etc.) and advanced training facilities of enterprises. In the long-term and stable cooperation, students and even teachers can directly participate in the design, production, transformation and other aspects of the enterprises, so that the enterprises have obtained stable human resources. Also, through the updating of human resources, the research, production and operation of enterprises can be continuously updated.

\section{SUMMARY}

School-enterprise cooperation has its fixed model. By constructing the same benefits of both, integrating education and practical resources, improving students' professional skills and quality, and providing excellent talents for enterprises. School-enterprise cooperation is not only good for the basic capacity building of colleges and professional construction and the construction of teachers, but also good for students to improve their practical skills and expand employment channels, and help enterprise to cultivate and select skilled talents. Questioners are provided by the students from Wuyi University, the ninety-four percent of the students participated in the college-enterprise cooperation are satisfied with the condition of enterprise, and they think the advantages of this teaching model are: internship conditions, internship guidance are guaranteed, subject counterpart and government policy guidance. They are summarized in Fig. 3 and Fig. 4 respectively. These students cultivated by college and enterprise are easier been recognized by enterprise than those who are not been trained, and the former can get a satisfied occupation with higher salary easily.

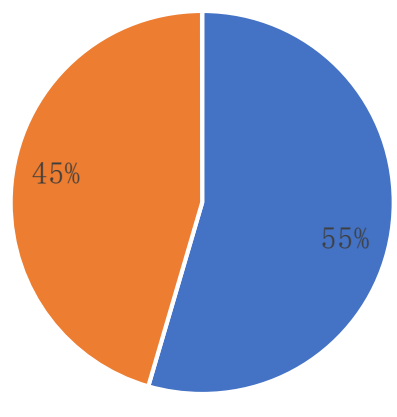

- Internship

Environment, Internship Guidance is Basically Guaranteed - Subject Counterpart

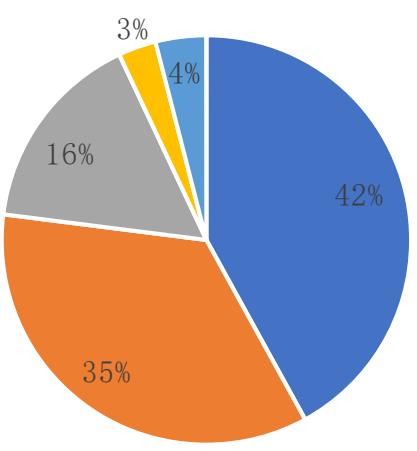

- Internship Environment, Internship Guidance is Basically Guaranteed - Sub ject

Counterpart

Fig. 4. Advantage of College-enterprise cooperation

\section{REFERENCES}

[1] Project of "Innovative Talents" of the Chinese Academy of Engineering. Towards Innovation - research on cultivation of innovative engineering science and technology talents[J]. Higher Engineering Education research, 2010(01): 1-19. (In Chinese)

[2] Qinghong QU. Study on the Cultivation of College Students' Employment Ability Under the Mode of the University-Enterprise Cooperation in Local Colleges and Universities[A]. International Association of Information and Engineering. Proceedings of 2016 4th International Conference on Management Science, Education Technology, Arts, Social Science and Economics (MSETASSE 2016) [C]. International Association of Information and Engineering:,2016:4.

[3] Lu Li. The Practical Research on the Joint Training of Excellent Engineers by School and Enterprise[D]. Sichuan Normal University,2015. (In Chinese)

[4] Liao C L, Polytechnic S. Exploration of Innovation and Entrepreneurship Education Based on the Promotion of College Students'employment Ability[J]. Education Teaching Forum, 2016.

[5] Bao Feng. Research on The Training Mode of Software Engineering School-Enterprise Cooperation talent[J]. Computer Knowledge and Technology,2014,10(09):1976-1977. (In Chinese)

[6] Zhao Hongxia. A Discussion on College-Enterprise Cooperation from Cultural Perspective[A]. Shanghai Xiao Yu Culture Communication Co., Ltd. Proceedings of The 2nd Asia-Pacific Management and Engineering Conference (APME 2016) [C]. Shanghai Xiao Yu Culture Communication Co., Ltd:,2016:6.

[7] Fu X, Feng H. Experience of Computer Science Education Reform Based on Enterprise-University Cooperation[J]. ermm-14, 2014.

[8] Li Gao. The Research of the Practical College's College-enterprise Cooperation Mode[A]. Singapore Management and Sports Science Institute, Singapore, Academic Conference Institute, USA. Proceedings of 2016 3rd International Conference on Management Innovation and Business Innovation(ICMIBI 2016 V57)[C].Singapore Management and Sports Science Institute, Singapore, Academic Conference Institute,USA:,2016:5.

[9] Wang Zhenhong, Shao Jiandong. Constructing the Interest Community and Promoting the Deep Cooperation between School and Enterprise[J]. China Higher Education,2011(Z1):61-63. (In Chinese)

[10] Wang Hongtao, Dong Chaojun, Huang Hui. Application Research of CDIO in Single Chip Microprocessor Based Graduation Design[A]. 11th International Conference on Innovation and Management (ICIM 2014) [C]. Univ Vaasa, Vaasa, han University of Technology, 2014.4: 12871290

[11] Wang Gang, Wang Xiumin, Yang Bing, Zhang Hongjun. Interaction Mechanism between School Enterprise Cooperation and College Students' Social Adaptability[J]. Occup and Health , 2014,30(21): 31263130. (In Chinese) 